\title{
DETEKSI ANOMALI TOTAL ELECTRON CONTENT SEBELUM GEMPA BUMI PALU MENGGUNAKAN JARINGAN SYARAF TIRUAN LEVENBERG-MARQUARDT
}

\author{
Bernadus Anggo Seno Aji ${ }^{1)}$, Arliyanti Nurdin²), Pangestu Widodo ${ }^{3)}$, Muh Rizal Dwi ${ }^{3)}$ \\ 1), 2), 3), 4) Teknologi Informasi, Institut Teknologi Telkom Surabaya \\ Jl. Gayungan PTT no 17-19, Surabaya \\ Email : bernadus.seno@ittelkom-sby.ac.id ${ }^{1)}$,arliyanti.n@ittelkom-sby.ac.id ${ }^{2}$, pangestu@ittelkom-sby.ac.id ${ }^{3)}$ \\ rizaldapramana@student.ittelkom-sby.ac.id ${ }^{4}$
}

\begin{abstract}
Abstrak
Indonesia termasuk kedalam negara dengan aktifitas gempa bumi yang tinggi. Analisis gempa bumi yang pernah terjadi sangat membantu dalam memahami karakteristik gempa bumi di Indonesia. Penelitian ini menggunakan Gempa bumi Palu $\left(0.18^{\circ} S 119.85^{\circ}\right.$ E) 2018 sebagai pengamatan dan menggunakan JST LM (Jaringan Syaraf Tiruan Levenberg-Marquardt) sebagai metode pembelajaran. Tujuan dari penelitian ini untuk menganalisis gempa bumi Palu dan menguji kesesuaian metode JST LM untuk mendeteksi anomali sebelum gempa bumi yang diamati. Hasil memperlihatkan bahwa metode ini cukup baik dalam mendeteksi anomali yang berasosiasi dengan gempa bumi Palu. Anomali yang terdeteksi didapat pada $\mathrm{H}-3$ dan $\mathrm{H}-\mathrm{O}$ sebelum gempa bumi terjadi, serta $H+1$ setelah gempa bumi. Dalam penelitian ini juga dianalisis pola distibusi anomali sepanjang garis lintang. Pola anomali menunjukkan terlokalisasi disekitar epicenter gempa bumi. Selain itu juga didapatkan pola anomali bergerak ke arah selatan searah dengan pergerakan Sesar Palukoro.
\end{abstract}

Kata kunci: Gempa Bumi, Jaringan Syaraf Tiruan, Levenberg-Marquardt

\section{Pendahuluan}

Indonesia merupakan negara yang sering terjadi gempa bumi. Salah satu gempa bumi besar yang terjadi adalah gempa bumi di Sulawesi khususnya daerah kota Palu pada 28 September 2018. Gempa bumi disertai tsunami tersebut mengakibatkan lebih dari 2000 korban jiwa dan lebih dari 50.000 rumah rusak. Berdasarkan kenyataan tersebut, perlu di lakukan suatu cara metigasi gempa bumi, salah satunya dengan memprediksi terjadiya gempa bumi yang akan terjadi. Beberapa cara yang sudah dilakukan untuk memprediksi gempa bumi yang akan terjadi antara lain menggunakan parameter geofisika ,beberapa penelitian menggunakan parameter geofisika untuk menentukan precursor gempa bumi. Menentukan precursor gempa bumi berdasarkan pengamatan magnetotllurik di observasi geofisika pelabuhan ratu (Fransiska, Setyawan and Nurdiyanto, 2013). Menentukan prekursor gempa bumi dengan mengidentifikasi anomali data geomagnetik frekuensi rendah dari Stasiun kelas III gunung sitoli, Nias (Hamidi,
Namigo and Ma'muri, 2018). Beberapa penelitian tersebut memperlihatkan adanya prekursor gempa bumi. Parameter geofisika sangat dipengaruhi lokasi sensor atau stasiun pengamat. Pada saat ini, ribuan GPS receiver digunakan untuk mengambil data Total Electron Content (TEC). Data TEC yang dihasilkan dari perhitungan GPS membuat kontribusi yang besar dalam memahami variasi seismo-ionosfer. Berdasarkan hal tersebut, dalam beberapa tahun terakhir analisis anomali TEC pada ionosfer dan hubungannya dengan gempa bumi sudah banyak diteliti untuk digunakan prediksi precursor gempa bumi. Pada penelitian ini, data TEC yang dianalisis menggunakan data Global Ionospheric Map (GIM) dari NASA Jet Propulsion Laboratory (JPL).

Beberapa metode yang pernah digunakan untuk mendeteksi precursor gempa bumi menggunakan anomali TEC antara lain Genetic Algorithm (Akhoondzadeh, 2013), metode ini menunjukkan hasil yang cukup baik untuk mendeteksi anomali TEC. GA dapat menjadi metode yang baik untuk memodelkan fenomena yang kompleks seperti prekursor gempa bumi, tetapi memilih nilai corssover, mutasi dan fitness rate serta jumlah pengamatan merupakan tantangan berat dalam pemodelan GA. Ada juga penelitian menggunakan Artificial Bee Colony (M Akhoondzadeh, 2015). ABC memperlihatkan kemampuan dalam mendeteksi data TEC yang irregular dan non linier. Selain kedua metode tersebut juga ada penelitian menggunakan Firefly Algorithm (Mehdi Akhoondzadeh, 2015). Penelitian menunjukkan kesesuain FA dalam mendekteksi anomali TEC. Selain itu ada salah satu penelitian yang sudah pernah dilakukan di Indonesia terkait gempa bumi Aceh pada 26 Desember 2004 menggunakan nu-SVR (Pattisahusiwa, Liong and Purqon, 2014). Metode tersebut cukup baik dalam mendeteksi variabilitas data TEC akibat gempa bumi.

Metode-metode tersebut digunakan karena sifat dari data TEC yang irregular, komplek dan non linier. Karena sifat data tersebut, diperlukan metode yang dapat menangangi permasalah tersebut. Pada penelitian ini digunakan 
metode Jaringan Syaraf Tiruan dengan LevenbergMarquardt untuk mendeteksi anomali TEC yang terjadi sebelum gempa bumi Palu. Metode Jaringan syaraf tiruan levenberg-marquardt dipilih karena terbukti stabil, lebih cepat dan efektif untuk data-data komplek dan non linier (Yu, M. and Wilamowski, 2004). Selain itu, metode ini sangat baik dan direkomendasikan untuk data dan jaringan dalam ukuran kecil dan sedang. Hal tersebut sesuai dengan data TEC yang hanya berukuran sedang (Yu, M. and Wilamowski, 2004). Setelah deteksi anomali pada TEC akan dilakukan analisis anomali yang terjadi terkait heliogeomagnetik dan gempa bumi.

\section{Pengolahan Data}

Gempa bumi yang digunakan adalah gempa bumi Palu 28 September 2018 seperti Tabel 1:

Tabel 1 Data Gempa Bumi yang diteliti

\begin{tabular}{|l|c|c|l|}
\hline \multicolumn{1}{|c|}{ Waktu } & Lat & Long & Tempat \\
\hline $\begin{array}{l}\text { 28-09-2018 } \\
\text { 10:02:43 UTC }\end{array}$ & 0.180 & 119.850 & Palu \\
\hline
\end{tabular}

Data TEC yang digunakan dari Global Ionospheric Maps (GIM) oleh National Aeronautics and Space Administration (NASA) dengan interval $5^{0} \times \quad 2.5^{0}$ (longitude, Latitude). Selain itu, pada penelitian ini geomagnetik data (Dst Indeks) digunakan untuk memisahkan anomali yang terjadi karena gempa bumi dengan anomali lainnya seperti anomali yang berkaitan dengan aktivitas geomagnetik, Dst Indeks digunakan untuk mengukur tingkat badai magnetik, dimana badai magnetik disebabkan oleh badai matahari yang berinteraksi dengan medan magnet bumi. Nilai Dst $<-30$ mengidentifikasikan bahwa aktivitas matahari sedang dalam keadaan yang tinggi atau terjadi badai matahari.

TEC diambil dari tanggal 1 Juli 2018 sampai 30 September 2018 pada koordinat yang paling mendekati epicenter gempa bumi yaitu $0^{0} \times 120^{\circ}$ (Latitude, Longitude) pada jam 18.00 UTC atau 00.00 WITA. Jam 00.00 dipilih karena pada jam tersebut aktivitas matahari dalam keadaan lebih tenang. Diharapkan pengaruh badai matahari dalam anomali TEC lebih kecil (Anggo et al., 2017).

Data TEC dibagi menjadi data training dan data testing. 1 Juli - 20 September 2018 digunakan sebagai data training. 21 - 30 September 2018 digunakan sebagai data Testing dan pengamatan gempa bumi. Selain itu, diambil data TEC pada koordinat lintang $-10^{0}$ sampai $10^{\circ}$ pada bujur $120^{\circ}$ untuk mengetahui distribusi anomali sepanjang garis lintang (Pattisahusiwa, Liong and Purqon, 2015).

\section{Metodologi}

Metode Jaringan Syaraf Tiruan Tiruan merupakan salah satu metode pelatihan non-linier yang sudah teruji. Metode JST LM merupakan varian dari metode JST. Algoritma Levenberg - Marquardt merupakan pengembangan dari algoritma backpropagation standar. Pada Backpropagation standar, proses meminimumkan eror dengan mengupdate bobot dan bias menggunakan negative gradient descent sedangkan pada algoritma levenberg-marquardt menggunakan pendekatan matriks Hesian yang dapat dihitung dengan,

$$
H=J^{T} e
$$

Sedangkan gradient dapat dihitung dengan,

$$
g=J^{T} J
$$

Dengan $\mathrm{J}$ merupakan matriks jacobian yang berisi turunan pertama dari nilai eror jaringan terhadap bobot dan bias. Perubahan bobot dapat dihitung dengan rumus berikut.

$$
\Delta X=\left[J^{T} J+\mu I\right]^{-} J^{T} e
$$

Sehingga update bobot dapat dihitung berdasarkan rumus,

$$
\begin{aligned}
& X=X+\Delta X \\
& X=X+\left[J^{T} J+\mu I\right]^{-} J^{T} e \\
& {\left[\begin{array}{ccc}
\frac{\partial e_{11}(x)}{\partial x_{1}} & \cdots & \frac{\partial e_{11}(x)}{\partial x_{n}} \\
\vdots & \ddots & \vdots \\
\frac{\partial e_{\mathrm{hp}}(x)}{\partial x_{1}} & \cdots & \frac{\partial e_{\mathrm{hp}}}{\partial x_{n}}
\end{array}\right]}
\end{aligned}
$$

$\mathrm{X}=$ fungsi bobot-bobot dan bias

E merupakan vektor yang menyatakan semua eror pada output jaringan

$$
e=\left[t_{1}-y_{1} t_{2}-y_{2} \ldots t_{p}-y_{p}\right]^{T}
$$

$\mu=$ Konstanta Learning

$I=$ Matrik Identitas

Penelitian ini menggunakan library Trainlm dan dijalankan dengan bantuan program Matlab R2018b, arsitektur JST LM yang digunakan adalah empat (4) neuron sebagai input layer, satu (1) hidden layer dengan tiga (3) neuron dan satu neuron pada output layer. Jaringan input dan output pada proses training sebagai berikut :

$$
\begin{aligned}
& X_{5}=f\left(X_{1}, X_{2}, X_{3}, X_{4}\right) \\
& X_{6}=f\left(X_{2}, X_{3}, X_{4}, X_{5}\right) \\
& \cdot \\
& \dot{X}_{n}=f\left(X_{n-4}, X_{n-3}, X_{n-2}, X_{n-1}\right)
\end{aligned}
$$

Proses training dijalankan kemudian menghasilkan eror yang dioptimasi menggunakan levenberg-marquardt sehingga didapatkan eror prediksi paling minimum. Selain itu, pada proses training, ditentukan batas-batas anomali yang akan digunakan untuk menentukan anomali yang terjadi. 
Batas anomali sebagai berikut,

$$
\text { Batas }=\mu \pm 2.0 \times \sigma
$$

$\mu, \sigma$ adalah rata-rata dan standar deviasi dari proses training.

Kemudian jaringan paling optimal digunakan pada proses testing. Jaringan input output pada proses testing sebagai berikut:

$$
\begin{aligned}
& X_{n+5}=f\left(X_{n+1}, X_{n+2}, X_{n+3}, X_{n+4}\right) \\
& X_{n+6}=f\left(X_{n+2}, X_{n+3}, X_{n+4}, X_{n+5}\right) \\
& \cdot \\
& \dot{X}_{n+m}=f\left(X_{n+m-4}, X_{n+m-9}, X_{n+m-2}, X_{n+m-1}\right)
\end{aligned}
$$

Anomali terdeteksi jika selisih nilai aktual dan nilai prediksi atau DTEC melebihi batas anomali.

\section{Pembahasan}

Hasil prediksi terhadap data TEC yang berkaitan dengan gempa bumi Palu menunjukkan adanya anomali sebelum terjadi gempa bumi (Gambar 1). Anomali terjadi tanggal 25 September 2018 atau H-3 sebelum gempa bumi dan tanggal 28 September 2018 atau pada hari H saat gempa bumi terjadi.
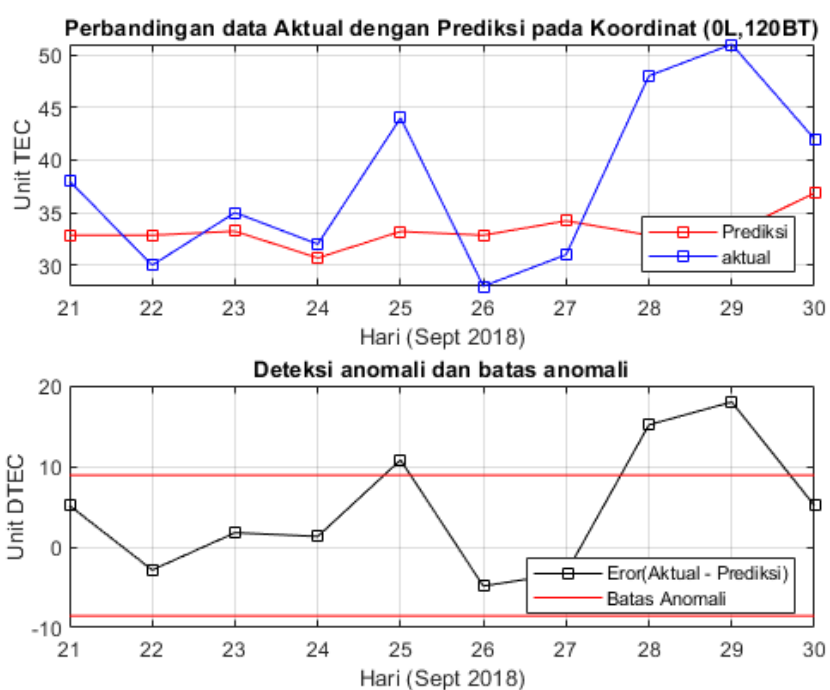

Gambar 1 (atas) prediksi TEC pada koordinat (0,120), (bawah) Deteksi dan batas anomali 21 - 28 September 2018.

Pada anomali H-3, aktivitas matahari menunjukkan keadaan normal, tetapi pada tanggal 22 September 2018 memperlihatkan terjadinya badai geomagnetik yang ditunjukkan oleh nilai Dst < -30 (Gambar 2) sehingga perlu dilakukan analisis lebih lanjut. Data anomali yang didapatkan, selanjutnya akan dianalisis pola distribusi anomali tersebut sepanjang garis lintang. Garis lintang diambil dari rentang $\left[-10^{\circ}, 10^{\circ}\right]$. Berdasarkan analisis sepanjang garis lintang, didapatkan informasi bahwa anomali pada tanggal 25 September 2018 tidak terjadi sepanjang garis lintang (Gambar 3) dan keadaan geomagnetik pada tanggal tersebut sedang dalam keadaan tenang (Gambar 2) sehingga dapat disimpulkan bahwa anomali tersebut kemungkinan besar berasosiasi dengan gempa bumi tanggal 28 september 2018.

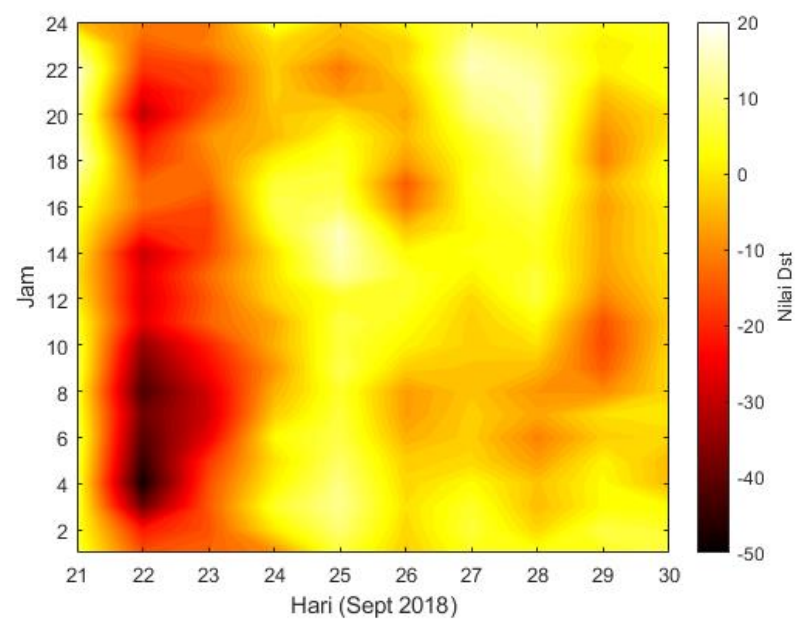

Gambar 2 Keadaan Geomagnetik 21 - 28 September 2018

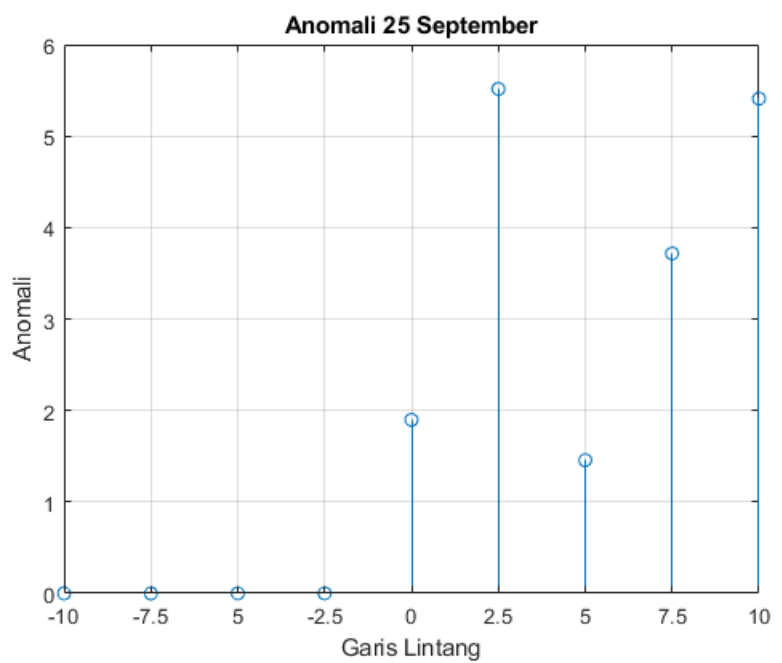

Gambar 3 Anomali (H-3) tanggal 25 September 2018 sepanjang garis lintang $[-10,10]$

Analisis kedua dilakukan untuk anomali pada hari kejadian gempa (H-0) pada tanggal 28 September 2018. Berdasarkan analisis tersebut, didapatkan informasi pola anomali yang terbentuk memperlihatkan pola terlokalisasi dengan titik puncak sekitar epicenter dan akan berkurang saat menjauhi epicenter (Gambar 4). Pada 28 September 2018 keadaan geomagnetik memperlihatkan keadaan yang tenang. Berdasarkan kedua fakta tersebut, anomali tanggal 28 september 2018 berasosiasi dengan gempa bumi pada tanggal yang sama

Analisis selanjutnya untuk anomali yang terjadi setelah gempa bumi terjadi. Anomali yang terjadi pada pada tanggal 29 September 2018 menunjukkan pola terlokalisasi dengan titik puncak pas di koordinat paling dekat dengan epicenter (Gambar 5). Walaupun ada beberapa koordinat yang tidak menunjukkan anomali, tetapi anomali yang terjadi masih menunjukkan pola terlokalisasi. Keadaan geomagnetik pada tanggal 
tersebut juga menunjukkan keadaan yang tenang, sehingga anomali pada tanggal 29 september 2018 berhubungan dengan gempa bumi yang terjadi.

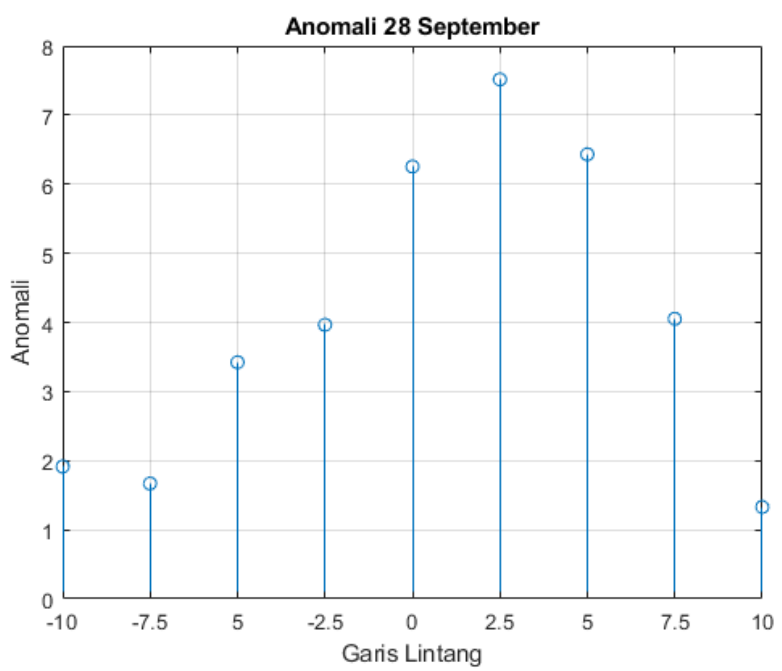

Gambar 4 Anomali (H-O) tanggal 28 September 2018 sepanjang garis lintang [-10,10]

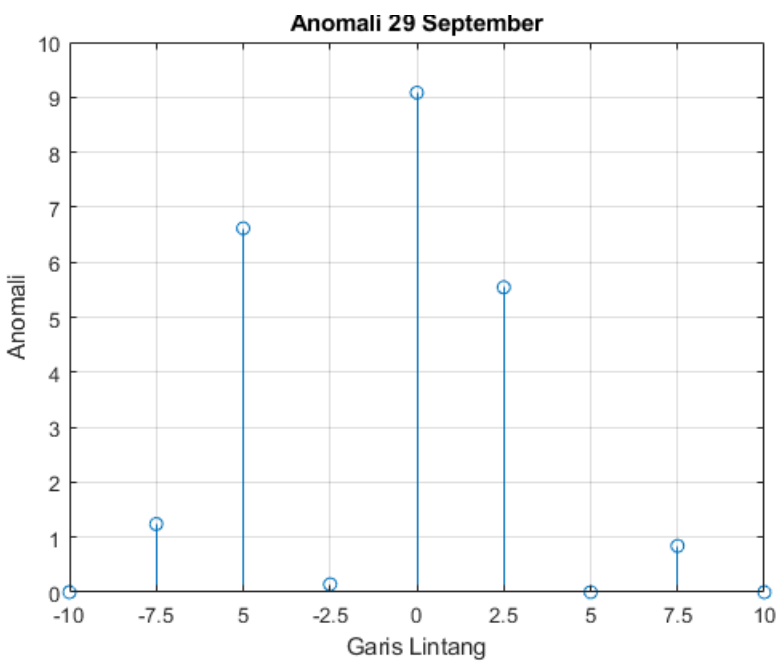

Gambar 5 Anomali $(H+1)$ tanggal 29 September 2018 sepanjang garis lintang $[-10,10]$

Berdasarkan informasi anomali yang terjadi dan analisis sepanjang garis lintang, anomali terkait dengan gempa bumi Palu terjadi pada $\mathrm{H}-3$ dan $\mathrm{H}-0$ serta $\mathrm{H}+1$ untuk keadaan setelah gempa bumi. Selain itu didapatkan informasi pola aliran anomali terlihat bergeser ke selatan (Gambar 3 - 5). Keadaan tersebut berkorelasi dengan deformasi yang terjadi pada gempa bumi Palu (Gambar 6). Berdasarkan dokumen yang disusun oleh Pusat Studi Gempa Nasional, dijelaskan bahwa gempa bumi Palu berasal dari pergeseran sesar Palu-Koro. Palu-Koro merupakan struktur geologi dengan mekanisme pergerakan mendatar mengiri (Sinistral Strike Slip). Sesar ini membelah Sulawesi menjadi dua bagian yaitu blok barat dan timur dari teluk Palu samapai teluk Bone.

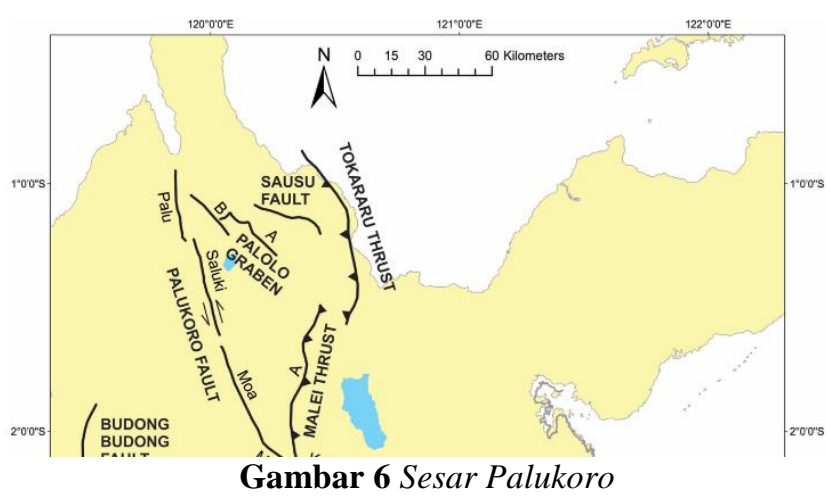

\section{Kesimpulan}

Metode Jaringan Syaraf Tiruan Lavenberg-Marquardt cukup baik dalam mendeteksi anomali yang terjadi pada data TEC. Anomali yang terjadi sebelum gempa bumi Palu, dideteksi H-3 dan H-0 sebelum gempa bumi serta $\mathrm{H}+1$ Setelah gempa bumi. Pola anomali yang terjadi cenderung terlokalisasi di sekitar epicenter gempa. Pergerakan anomali memperlihatkan pergerakan ke kiri, sesuai dengan keadaan deformasi sesar Palu-Koro yang mempunyai pegerakan mendatar kekiri (Sinistral Slip Strike). Diperlukan penelitian lebih lanjut untuk menguji hasil yang telah didapatkan, sehingga lebih valid. Perlu dilakukan analisis terhadap gempa-gempa bumi lainnya sehingga proses pembelajaran terhadap karakeristik gempa bumi di Indonesia lebih jelas.

\section{Daftar Pustaka}

Akhoondzadeh, M. (2013) 'Genetic algorithm for TEC seismoionospheric anomalies detection around the time of the Solomon (Mw = 8.0) earthquake of 06 February 2013', Advances in Space Research. COSPAR, 52(4), pp. 581-590. doi: 10.1016/j.asr.2013.04.012.

Akhoondzadeh, M (2015) 'Application of Artificial Bee Colony algorithm in TEC seismo-ionospheric anomalies detection', Advances in Space Research. COSPAR, 56(6), pp. 1200-1211. doi: http://dx.doi.org/10.1016/j.asr.2015.06.024.

Akhoondzadeh, Mehdi (2015) 'Firefly Algorithm in detection of TEC seismo-ionospheric anomalies', Advances in Space Research. COSPAR, 56(1), pp. 10-18. doi: 10.1016/j.asr.2015.03.025.

Anggo, B. et al. (2017) 'Detection Precursor of Sumatra Earthquake Based on Ionospheric Total Electron Content Anomalies using NModel Articial Neural Network', pp. 269-276.

Fransiska, N., Setyawan, A. and Nurdiyanto, B. (2013) 'PENENTUAN PREKURSOR GEMPA BUMI MENGGUNAKAN DATA', Youngster Phisics, 1(4), pp. 115-120.

Hamidi, M., Namigo, E. L. and Ma'muri, M. (2018) 'ULTRA LOW FREQUENCY SEBAGAI PREKURSOR', 10(1), pp. 53-62.

Pattisahusiwa, A., Liong, T. H. and Purqon, A. (2014) 'Pola Anomali Data Temporal Total Electron Content ( TEC ) Ionosfer yang Pola Anomali Data Temporal Total Electron Content ( TEC ) Ionosfer yang Berhubungan dengan Dua Gempa Besar Terkini di Indonesia', (March 2015). doi: 10.13140/2.1.1054.0322.

Pattisahusiwa, A., Liong, T. H. and Purqon, A. (2015) 'A method for separating seismo-ionospheric TEC outliers from heliogeomagnetic disturbances by using nu-SVR', 060009(JANUARY), p. 060009. doi: $10.1063 / 1.4930689$. 
Yu, H., M., B. and Wilamowski (2004) 'Levenberg-Marquardt Training, Physics of the Solid State, 46(8), pp. 1404-1409. doi: 10.1134/1.1788770. 